\title{
Bacterial Cellulose Production and its Industrial Applications
}

\section{Sherif MAS Keshk ${ }^{1,2 *}$}

${ }^{1}$ King Khalid University, Faculty of Science, Chemistry Department, P.O. Box 9004, Abha 61413- Saudi Arabia

${ }^{2}$ Ain-Shams University, Faculty of Environmental Studies and Research, Basic Science Department, Abbassia, Cairo 11566, Egypt

\begin{abstract}
Microbial cellulose has proven to be a remarkably versatile biomaterial and can be used in wide variety of applied scientific endeavors, such as paper product, electronics and biomedical devices. In fact, biomedical devices recently have gained a significant attention owing to increase in tissue-engineering products for both wound care and the regeneration of demand or diseased organs. So, microbial cellulose production, characterization and influence of additives during its production are important to understand the microbial pathway and create new application.
\end{abstract}

Keywords: Bacterial Cellulose; Fiber Structure; Production Enhancement; Medical Application

\section{Introduction}

Cellulose is the earth's major biopolymer and is of tremendous economic importance globally. Cellulose is the major constituent of cotton (over 94\%) and wood (over 50\%). Together, cotton and wood are the major resources for all cellulose products such as paper, textiles, construction materials, and cardboard, in addition to cellulose derivatives such as cellophane, rayon, and cellulose acetate. Cellulose from major land and forest plants and cotton is assembled from glucose, which is produced in the living plant cell from photosynthesis. In the oceans, however, most cellulose is produced by unicellular plankton or algae using the same type of carbon dioxide fixation found in photosynthesis of land plants. In fact, it is believed that these organisms, the first in the vast food chain, represent nature's largest resource for cellulose production. Without photosynthetic microbes, all animal life in the oceans would cease to exist. Several animals, fungi, and bacteria can assemble cellulose. However, these organisms are devoid of photosynthetic capacity and usually require glucose or some organic substrate synthesized by a photosynthetic organism to assemble their cellulose. Several excellent reviews and papers concerning the nature of cellulose structure and biosynthesis have appeared and some of the unifying features are recounted [1-4]. This review offers synopsis of the many recent developments reported for nature of its fibril structure, enhancement of bacteria cellulose production and influence of several organic additives on the crystal structure of bacterial cellulose as well as its applications in several industries.

\section{Microbial cellulose: A source of pure cellulose}

Among the bacteria, one of the most advanced types of purple bacteria is the common vinegar bacterium, Acetobacter. This nonphotosynthetic organism can procure glucose, sugar, glycerol or other organic substrates and convert them into pure cellulose [5,6]. Unlike the cellulose from wood pulp, cellulose produced by an Acetobacter strain is devoid of other contaminating polysaccharides and its isolation and purification are relatively simple, not requiring energy- or chemicalintensive processes. Further more, environmental problems due to byproducts of wood pulping given an added impetus to study unexplored sources of cellulose [7]. There is no single system, which has emerged as an ideal system for the study of cellulose biosynthesis. For those new to the field, it is helpful to describe briefly some that have proven particularly useful. Very few genera of bacteria can synthesize cellulose, but the gram-negative bacterium Gluconacetobacter xylinus (Formerly known as Acetobacter xylinum) secretes large quantities of cellulose as microfibrils from a row of synthetic sites along the longitudinal axis of the cell $[8,9]$. The microfibrils from each synthetic site merge to form a large ribbon of cellulose; in the growth medium. These ribbons and the associated cells tangle form a floating pellicle that allows the non-motile, strictly aerobic bacteria to grow in the higher oxygen tension at the surface of the growth medium. Upon contact with host plant cells, the tumor-forming bacterium Agrobacterium tumefaciens secrets cellulose fibrils from all sides of the cell, a process that aids in cell attachment and promotes virulence $[10,11]$. Both Gluconacetobacter xylinus and Agrobacterium tumefaciens can be grown in large quantities and can be transformed. Mutants of both can be selected that are impaired in cellulose biosynthesis and genes and enzymes involved in this process have been identified in both bacteria. The cellulosic algae have proven quite useful for freeze-fracture studies in which putative synthase complexes were first visualized in the plasma membrane, but they have proven difficult to study at the biochemical and molecular levels [5]. Algal cellulose from different origins has been analyzed with special reference to the crystalline features such as allomorphism, dimension [12]. The slim mold Dictyostelium discoideum synthesizes cellulose at various stages in its life cycle. A cellulose synthase activity has been demonstrated in this organism [13] and many sophisticated genetic approaches are available that make it very attractive for developmental studies of cellulose biosynthesis. The water mold Saprolegnia contains both 1,4- $\beta$-D-glucan and $\beta$-D-1,3-glucan in its cell walls and separable enzymes have been detected that synthesize these glucans in vitro, but genetic studies are not advanced with this organism [14]. In higher plants, cotton fibers represent an interesting object of study [15]. These are single cells that elongate from the epidermal layer of the ovule and they elongate synchronously within the boll. There is no experimental evidence that bacterial cellulose biosynthesis differs from those of green plants, but Uridine Diphosphoglucose (UDPG) is necessary intermediate in the synthesis of bacterial cellulose while Guanidine Diphosphoglucose (GDPG) is involved in the biosynthesis of green plant cellulose [7]. A good model system to study the mechanism of cellulose biogenesis is the bacterium Gluconacetobacter xylinus

*Corresponding author: Sherif Mohamed Abdel Salam Keshk, King Khalid University, Faculty of Science, Chemistry Department, P.O. Box 9004, Abha 61413- Saudi Arabia, Tel: 966509754436; E-mail: keshksherif@gmail.com

Received January 09, 2014; Accepted January 28, 2014; Published February 03, 2014

Citation: Keshk SMAS (2014) Bacterial Cellulose Production and its Industrial Applications. J Bioprocess Biotech 4: 150 doi: 10.4172/2155-9821.1000150

Copyright: (c) 2014 Keshk SMAS. This is an open-access article distributed unde the terms of the Creative Commons Attribution License, which permits unrestricted use, distribution, and reproduction in any medium, provided the original author and source are credited. 


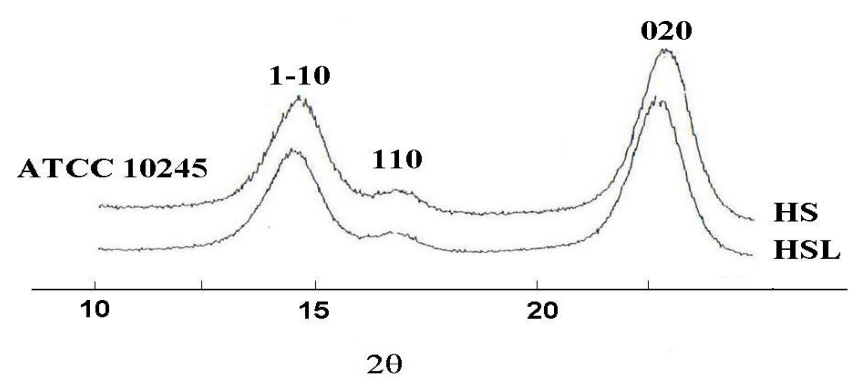

Figure 1: X-ray pattern of BC produced from HS and HSL media in presence of Gluconacetobacter xylinus ATCC 10245.

that produces pure cellulose as an extracellular product. Figure 1 explains the proposed model for regulation of cellulose synthesis in Gluconacetobacter xylinus [16-21].

\section{Bacterial cellulose fibril structure}

Application of solid state 13C NMR analysis to cellulose from 1980 taken a new turn for structural analysis of cellulose I, which indicate that native cellulose consist of two different crystal structures, cellulose $\mathrm{I}_{\alpha}$ and $\mathrm{I}_{\beta}[22,23]$. The primary difference between cellulose $\mathrm{I}_{\alpha}$ and $\mathrm{I}_{\beta}$ appears at the pattern of $\mathrm{C} 1$ resonance around $106 \mathrm{ppm}$, singlet resonance for $\mathrm{I}_{\alpha}$ and doublet one for $\mathrm{I}_{\beta}$. Hirai et al. [24] reported that almost pure cellulose $I_{\beta}$ could be prepared from cellulose $I_{\alpha}$-rich samples by hydrothermal treatment under slightly alkaline conditions at $260^{\circ} \mathrm{C}$ for $30 \mathrm{~min}$. Since cellulose $\mathrm{I}_{\beta}$ is formed irreversibly from cellulose $\mathrm{I}_{\alpha}$, the structure of cellulose $\mathrm{I}_{\beta}$ must be thermodynamically more stable than that of cellulose $\mathrm{I}_{\alpha}$. Cellulose $\mathrm{I}_{\alpha}$ is crystallize in larger-size microfibrils, whereas cellulose $I_{\beta}$ is formed in smaller-size microfibrils. Cellulose I must be crystallized in the higher energy state compared to the case of cellulose $\mathrm{I}_{\beta}$, because the crystal transformation is induced from cellulose $I_{\alpha}$ to $I_{\beta}$ at higher temperatures. The unit cell of cellulose $I_{\alpha}$ is a triclinic and that for cellulose $I_{\beta}$ is monoclinic unit cell [25].It seems almost acceptable that native cellulose crystals are composites of two allomorphs, cellulose $\mathrm{I}_{\alpha}$ and $\mathrm{I}_{\beta}$ [26], although there is some significant exception in nature [25,27]. The ratio of cellulose $I_{\alpha}$ and $I_{\beta}$ differs greatly from species to species [25]. Why do two allomorphs exist and why does their ratio vary in nature. One approach to answering these questions is to characterize the crystallization process for a cellulose-producing bacterium, Gluconacetobacter xylinus, as a model system. The biosynthesis of cellulose by this bacterium has been relatively well studied and their ratio is changed depending on the culture conditions, e.g. additives and temperature [28,29]. According to the recent structural model [30], several tens of cellulose synthesizing sites are located in the cytoplasmic membrane, being aligned parallel with the longitudinal axis of the bacterial cell. Cellulose synthases in the respective sites produce 12-15 cellulose chains and extrude them into the culture medium as fine fibrils with a lateral width of about $1.5 \mathrm{~nm}$ (such fine fibrils are often called supplementary fibrils) through small pores in the outer membrane. These supplementary fibrils aggregate to form microfibrils 3-6 $\mathrm{nm}$ in width, and the resulting microfibrils further aggregate to produce a typical ribbon assembly with a lateral width of $40-60 \mathrm{~nm}$. The term of microfibril has been proposed to denote the thinnest fibril structures visible in the field of the electron microscope. Crystallization of cellulose will be induced during the aggregation processes because the supplementary fibrils may be too fine to crystallize. Sea algal cellulose and bacterial cellulose, which is produced by Gluconacetobacter xylinus, are found to be rich in $\mathrm{I}_{\alpha}$; the average mass fraction of cellulose $\mathrm{I}_{\alpha}$ is about 0.63 . For example, the mass fractions of cellulose I are 0.64 for Valonia macrophysa; 0.60 for Valonia aegarropila, 0.67 for Chaetomorpha. In the case of bacterial cellulose, the mass fraction also depends on strains and culture temperature, ranging from 0.64 to 0.71 . Careful purification with aqueous alkaline solution will also induce the reduction of the content of cellulose $I_{\alpha}$ by high percent in bacterial cellulose. On the other hand, cellulose forming cell walls for higher plants such as cotton and ramie is rich in cellulose $I_{\beta}$, the mass fraction being about 0.8 , as for the characterization of wood [25]. Bacterial cellulose can be produced by two kinds of culture method, namely static and agitated [31]. Under static culture conditions a typical gelatinous membrane of bacterial cellulose is accumulated on the culture surface whereas, under agitated culture conditions bacterial cellulose is produced in well-dispersed slurry as irregular masses such as granule, stellate and fibrous strand. The agitated culture method seems to be suitable for the industrial production of bacterial cellulose and serves commercial application in various fields. The static culture method has been adopted mainly for the investigation of cellulose production because cellulose deficient mutants sometimes appear in agitated cultures; these mutants were believed to interfere with the fermentative production of bacterial cellulose [31]. Several researchers, however, have succeeded in producing bacterial cellulose using stable cellulose-producing strains in agitated culture $[31,32]$. Nevertheless, a patent claimed that a specific reticulated structure observed by scanning electron microscopy was generated in bacterial cellulose produced in agitated culture, but not in that produced in static culture. Watanabe et al. [31] revealed that bacterial cellulose produced in agitated culture had a lower degree of polymerization (DP) and crystallinity compared with that produced in static culture. These finding suggest that the smaller particle size of agitated bacterial cellulose lead to a higher water holding capacity (WHC) than static bacterial cellulose. ACP/ MAS ${ }^{13} \mathrm{C}$ NMR analysis revealed that the cellulose I $\alpha$ content of the cellulose produced in agitated culture was lower than that of the cellulose produced in static culture. Therefore it has a lower Young's modulus of sheet, higher water holding capacity and a higher suspension viscosity in the disintegrated form than produced in static culture [32].

\section{Biosynthesis of cellulose from various carbon sources}

In general, glucose has been used as a carbon source for cellulose production by A. xylinum. It has been reported, however, that cellulose was also synthesized from other carbon sources, such as 5- or 6-carbon monosaccharides, oligosaccharides, starch, alcohol and organic acids [33]. Fructose and glycerol gave almost the same cellulose yield as glucose [34]. The yield of cellulose, relative to the glucose consumed, decreased with an increase in initial glucose concentration, and gluconic acid accumulated at a high initial glucose concentration. The decrease in cellulose yield could be due to some glucose being metabolized to gluconic acid. The optimum $\mathrm{pH}$ for cellulose production is between 4.0 to 6.0. Production of cellulose from D-arabitol by Gluconacetobacter xylinus KU-1 (it was obtained from the type culture collection of the laboratory of applied biological chemistry, Yamaguchi University, Japan) was studied [35]. The amount of cellulose from D-arabitol was more than 6 times as much as that from $\mathrm{D}$-glucose. In D-arabitol medium, the final $\mathrm{pH}$ did not decrease and D-gluconic acid was not detected, this seems to be one of the reasons for high productivity of cellulose from D-arabitol. Romano measured the yield of cellulose from glucose, galactose or xylose as a carbon source. Galactose and xylose gave smaller yields, mostly because of slower growth rates. The microfibrils obtained from xylose are also less regular than those obtained from glucose. Gas chromatography analysis showed that the composition of sugars in the polymers (cellulose and other by-product) produced from xylose as a 
carbon source were still $80 \%$ glucose and $20 \%$ other sugars, and there were no differences in the degree of polymerization. Times initiation of production was also different for the different carbon sources. The use of the cheaper carbon sources might be able to reduce the production cost. Bacterial cellulose yield from sucrose is only half those from glucose, it is due to the low activity of sucrase in A. xylinum. If sucrose is efficiently hydrolyzed, it will increase bacterial cellulose productivity. Tajima et al. [36] have succeeded in enhancing bacterial cellulose productivity by the co-cultivation of two different types of Gluconacetobacter xylinus strains (NCI 1051 or ATCC 10245 and NCI 1005). The bacterial cellulose productivity of Gluconacetobacter xylinus by co-cultivation was greater than that by monocultivation. This seems to be due to the formation of glucose and fructose through the hydrolysis of sucrose by sucrase secreted from Gluconacetobacter xylinus NCI 1005. These researchers used Gluconacetobacter xylinus strains (IFO, ATCC or NCI) while other studies employed Gluconacetobacter xylinus, the nata organism, which was isolated directly from a nata. Nata is a favorite dessert delicacy native to the Philippines and produced mainly in the coconut regions. The cellulose "gel" or nata is synthesized by a strain of Gluconacetobacter xylinus grown in coconut water or fruit juices (pineapple, tomato, etc.) supplemented with sucrose [37,38]. In this case, fructose gave the best yield, followed by a combination of fructose + lactose. Sucrose and a combination of fructose + lactose also gave good yields. These four carbohydrate sources gave significantly better yields than any of the other sources. The presence of glucose in the medium alone or in combination with other sugars produced lower amounts of cellulose. The cellulose yields from sucrose, although lower than those from fructose.

\section{Enhancement of bacterial cellulose production}

Bacterial cellulose production has been reported to be enhanced by the addition of a small amount of a cellulase complex (cellulase complex has endoglucanase, exocellobioglucosidase and $\beta$-glucosidase activities and cellulose binding) to the culture broth [39]. Tonouchi et al. [40] examined cellulose production by Gluconacetobacter xylinus using a single species of $\beta$-1,4-endoglucanase and its active site mutant, which still had cellulose-binding ability, but was devoid of the enzyme activity, to identify the effect of the cellulose-binding ability on cellulose production. They found that the endoglucanase activity itself, not the cellulose-binding ability, enhanced bacterial cellulose production. The addition of small amount cellulase does not affect the degree of polymerization of the bacterial cellulose but enhance the production rate [40]. It has been found that the addition of a commercial sulfite pulping waste fraction (named CP powder) into culture medium remarkably enhanced the efficiency for cellulose production of Gluconacetobacter xylinus [41]. The CP powder was fractionated by gel filtration with Sephadex G-25 into the high and low molecular fractions (named A and $\mathrm{B}$ ) and it was clarified that the high molecular lignosulfonate fraction (A) was essential for the remarkable yield increase in the cellulose production of Gluconacetobacter xylinus. Premjet et al. [42] found a simpler separation method as follow; the larger amount of $\mathrm{CP}$ powder was treated by single ethanol precipitation and divided into a precipitate (high molar fraction, C) and nonprecipitate (low molar fraction, D). Fraction C consists mainly of high molecular lignosulfonate almost equivalent to fraction $\mathrm{A}$ (which separate by Sephadex G-25) and shows low sugar contents and strong $\mathrm{UV}$ absorption at $280 \mathrm{~nm}$. Fraction D, which shows high sugar contents and lower UV absorption is almost equivalent to fraction B (which separate by Sephadex G-25) and is deduced to consist mainly of the low molecular weight carbohydrates and the low molecular weight lignosulfonate. Fraction A differs from fraction $\mathrm{C}$ in that the former contains UV absorbing substance in the $\mathrm{D}$ region. Fraction $\mathrm{B}$ also has a little UV absorption in $\mathrm{C}$ region. Both fraction $\mathrm{A}$ and $\mathrm{B}$ greatly affected the cellulose production [41]. In which, fraction A is much more effective than fraction $B$. The remarkable yield increase by the addition of fraction A means that the ethanol precipitation method is equally effective as the gel-filtration method to separate the substance which contribute to the remarkable yield increase from the whole $\mathrm{CP}$ powder. Fraction A was further purified by the repetition of ethanol precipitation to give precipitate (fraction A1) and non-precipitate (fraction A2) then fraction $\mathrm{A} 1$ was further purified to give precipitate (fraction A3) and non-precipitate (fraction A4). It was observed that high molecular fraction A3 gave the highest efficiency and the low molecular fraction A2 and A4 were followed [41]. This indicates that the fraction A3 is the highly purified high molecular lignosulfonate with the lowest sugar content. The efficiency of fraction A3 is about two times larger than those of fractions $\mathrm{C}$ and A. From these results the carbohydrates in $\mathrm{CP}$ powder do not play any important role on the cellulose production. The more the high molecular lignosulfonate fraction was purified the more the efficiency for cellulose production increased. This means that the purification to eliminate both carbohydrates and low molecular fraction is effective. The prominent cellulose productivity was also observed by the addition of either sodium or calcium lignosulfonates on the market, which indicates that the high molecular lignosulfonate in CP powder is the dominant contributor for the high cellulose productivity [41]. Influence of Vitamin C (Ascorbic acid) on bacterial cellulose (BC) production and crystal structure was studied using four strains of Gluconacetobacter xylinus (ATCC 10245, IFO 13693 , 13772 and 13773) [43]. BC productivity of all strains was increased in presence of Vitamin $\mathrm{C}(0.5 \% \mathrm{w} / \mathrm{w})$, the average $\mathrm{BC}$ production reached to $0.47 \mathrm{~g} / 30 \mathrm{ml}$ compared with $0.25 \mathrm{~g} / 30 \mathrm{ml}$ without Vitamin C. Enhanced productivity is associated with a decrease in gluconic acid concentration that produced from Gluconacetobacter xylinus during $\mathrm{BC}$ production. X-rays results, showed, the crystallinity index of $\mathrm{BC}$ produced in presence of ascorbic acid was the lowest with remarkable change in d-spacing. These results confirmed by using solid state ${ }^{13} \mathrm{CNMR}$. The increase in $\mathrm{BC}$ yield in presence of Vitamin $\mathrm{C}$ is due to its antioxidant behavior and confirms our past work on lignosulfonate influence on BC.

\section{Influence of the additives on the crystal structure of BC}

Lignosulfonate: The influence of lignosulfonate on $\mathrm{BC}$ structure and productivity was studied using six strains of G. xylinus (ATCC 10245, IFO 13693, 13772, 13773, 14815 and 15237) [44]. BC productivity of all strains was improved almost $57 \%$ in the presence of $(1 \% \mathrm{w} / \mathrm{v})$ lignosulfonate. Ft-IR result showed that $\mathrm{BC}$ produced in the presence of lignosulfonate displayed the higher crystallinity idex and I -rich cellulose. Furthermore, X-ray diffractogram confirmed the FT-IR results and showed no remarkable change in d-spacing (Figure 1). From $\mathrm{CP} / \mathrm{MAS}{ }^{13} \mathrm{C}$ NMR spectra (Figure 2), the amorphous region in the presence of lignosulfonate was relatively lower, that means the lignosulfonate enhanced the crystalinity of BC. These results indicate that the increase in $\mathrm{BC}$ yield is due to the inhibition of gluconic acid formation in the presence of the antioxidant, polyphenolic compounds in the lignosulfonate. Furthermore, a scanning electron micrograph showed the ribbons that were produced in presence of lignosulfonate are coarse and less entangled compared with the ribbons that were produced by the control medium [44].

Moreover, the average Young's modulus was $633.00 \mathrm{Mpa}$ compared with $450.76 \mathrm{Mpa}$ in absence of lignosulfonate (Figure 3). It was also 


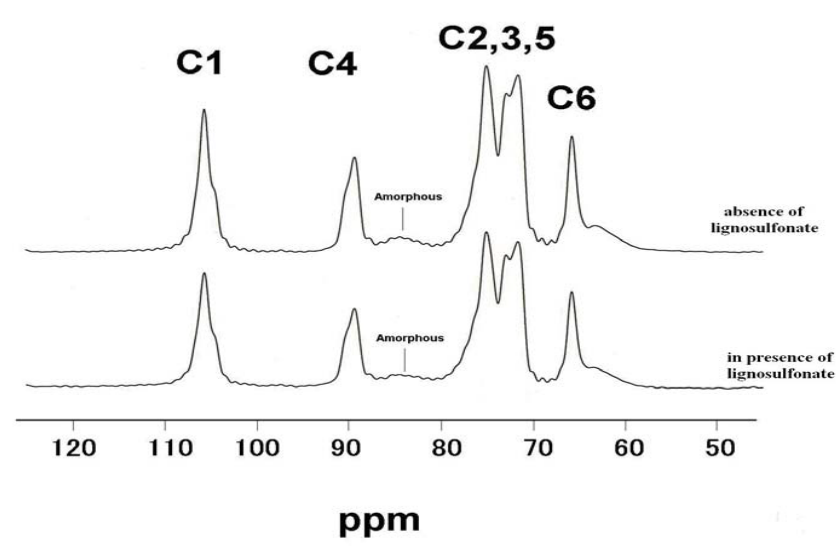

Figure 2: Solid state ${ }^{13} \mathrm{C}$ NMR spectra of $B C$ produced from HS and HSL media in Presence of G. xylinus ATCC 10245.
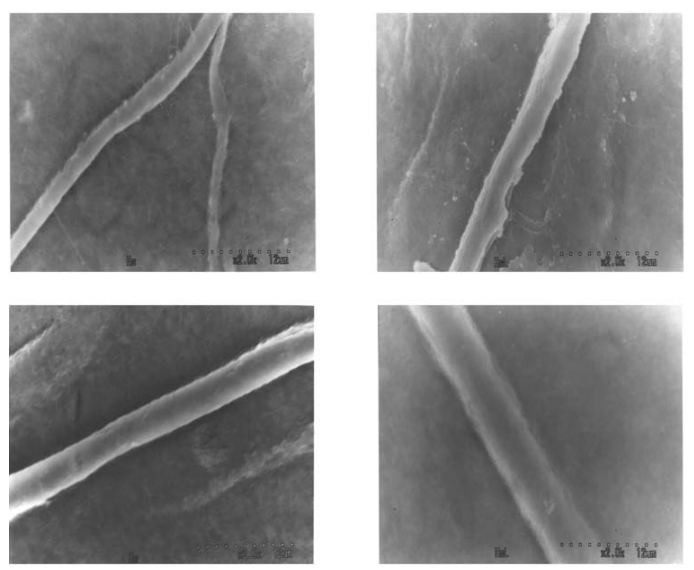

Figure 3: Scanning Electron Micrographs $(12 \mu \mathrm{m})$ of (Left) Bacterial cellulose in control medium. (Right) Bacterial cellulose in lignosulfoante medium.

\begin{tabular}{|c|c|c|c|c|c|}
\hline Sample & $\begin{array}{c}\text { BC* } \\
\text { Yield } \\
\text { mg/ml }\end{array}$ & $\begin{array}{c}\text { Tensile } \\
\text { Strength } \\
\text { (N) }\end{array}$ & $\begin{array}{c}\text { Young's } \\
\text { Modulus } \\
\text { (MPa) }\end{array}$ & $\begin{array}{c}\text { BC Viscosity } \\
\text { (cP) }\end{array}$ & DP \\
\hline HS 10245 & 4.4 & 10.0 & 331.75 & 34.87 & 1747.71 \\
\hline HSL 10245 & 7.2 & 18.28 & 606.45 & 70.05 & 2240.61 \\
\hline HS 13772 & 8.7 & 15.51 & 514.55 & 37.12 & 1791.40 \\
\hline HSL13772 & 11.4 & 18.69 & 620.05 & 84.80 & 2377.81 \\
\hline HS 13773 & 10.1 & 15.03 & 498.62 & 37.05 & 1790.08 \\
\hline HSL 13773 & 16.2 & 19.23 & 637.95 & 84.25 & 2372.80 \\
\hline HS 13693 & 7.9 & 13.81 & 458.15 & 36.88 & 1786.86 \\
\hline HSL 13693 & 16.3 & 21.53 & 714.27 & 68.82 & 2227.89 \\
\hline
\end{tabular}

${ }^{*}$ Based on the volume of the medium

$\mathrm{RV}=$ relative value $=$ yiled in $\mathrm{HS}$ / yiled in $\mathrm{H}$

Table 1: Characterization of Bacterial Cellulose and the Sheets Produced from Four Strains of Gluconacetobacter xylinus.

found that the average viscosity values of the produced sheets from lignosulfonate medium was $76.98 \mathrm{cP}$ compared with $36.48 \mathrm{cP}$ from control medium, which indicates a high degree of polymerization.

The ribbon morphology was estimated by electron microscopy from both HS and HSL media [44]. The electron micrographs of the two samples are presented in Figure 3. The morphology of these two samples was not the same as observed in Figures in which the morphology of BC produced from HS comprises thin ribbon compared with thick ribbon that were produced from HSL medium. The ribbons produced in the presence of lignosulfonate appeared coarser and less entangled than the ribbons produced by the control medium [44]. Since 1976, Brown et al, have interesting cytological observations on the mode of ribbon production at cell division. In which, the long row of microfibril synthesizing sites is longitudinally duplicated prior to division and that both parent and daughter sites are active just before division. The two sites are intercepted at cell fission, and each daughter cell receives a comparable set of synthesizing complexes, which does not extend in length and which synthesizes a microfibrillar ribbon at constant dimensions.

The two sites are intercepted at cell fission, and each daughter cell receives a comparable set of synthesizing complexes, which does not extend in length and which synthesizes a microfibrillar ribbon at constant dimensions.

This means that, the fibrils of $\mathrm{BC}$ is, perhaps, formed by the bunching of microfibrils, which are excreted from pores aligned on the surface of the cells in a row along their longitudinal axis. If the excretion continues beyond cell generation, the microfibrils of parent cells will inherit one-half by each of the daughter cells, forming a branching point on the fibril, so the diameter of fibril may be narrower after cell division, although it must recover as the new cell matures. Alternatively, the normal number of pores for excreting microfibrils will be provided in the new cells at the stage of division as suggested by Brown et al. [5]. In the presence of lignosulfoante, cell division appears to be inhibited, and the ribbons do not split and adjacent ribbons could to merge to form wider ribbons or aggregates of ribbons [44]. Thus adding lignosulfonate produced ribbons which appear wider than the ribbon in the control medium, because several ribbons from a cluster of cells whose dividing process was inhibited. The effects of the lignosulfoante on the tensile strength and Young's modulus for BC sheets are listed in Table 1.

The sheets made from $\mathrm{BC}$ cultivated for 30 days at $28^{\circ} \mathrm{C}$ on adding lignosulfonate gave $20-56 \%$ higher Young's modulus than those from the control sheets. Furthermore, the viscosity and the degree of polymerization of $\mathrm{BC}$ sheets produced from HSL were higher than those from the control medium (Table 1). These results are attributed not only to the increase in the effective cross-sectional area that produces an increase in cross-sectional momentum but also the increase in the number of 1,4 covalent bond. Hence, the wider ribbons gave a better uniplanar orientation, which produced a higher Tensile strength and Young's modulus. One factor that gave a higher Young's modulus of sheets made from $\mathrm{BC}$ is considered to be its ribbon form, because ribbons are more easily oriented in one plane when they are pressed [45]. These results matched with Huang et al., results. Where they studied the effect of lignosulfonate on properties of soy protein plastics and showed that, the introduction of lignosulfonate enhanced the tensile strength and Young's modulus of soy protein plastics.

Hemicellulose: Hemicellulose is also one of the main components of liginified cell wall. Monosaccharide residue constituting hemicelluloses are arabinose and xylose (pentose), glucose, galactose and mannose (hexose), rhamnose and fucose (6-deoxyhexose) and galacturonic, glucuronic and 4-O-methylglucuronic acids (Uronic acids). The dominating hemicellulose in hard wood is an O-acetyl (4-O-methylglucurono) xylan (so called hard wood xylan) accompanied by a small amount of glucomannan. On the other hand, softwood contains an O-acetylgalactomannan (so-called softwood glucomannan) as the major hemicellulose with a small amount of an arabino (4-O-methylglucurono) xylan (so-called softwood xylan). 
Cellulose produced in presence of hemicellulosic polysaccharides altered crystallinities and were found to be more like the $\mathrm{I}_{\beta}$-type crystalline structure. Mannan is believed to lower the degree of crystallinity of cellulose by decreasing the crystallite size, while xylan and xyloglucan are likely to co-crystallize with the cellulose and change the cellulose lattice structure by creating lattice defects $[46,47]$. The high affinity of xyloglucan for bacterial cellulose corresponds with xyloglucan-cellulose networks in the primary cell wall. In the case of secondary cell wall, however, the situation is not simple, because hemicellulsoe is chemically associated with lignin. It is recommended to use native hemicellulose present in woody plants for further investigation of the arrangement of cellulose-hemicellulose composites in the secondary cell walls of higher plant. For revelation of the affinity between cellulose and hemicellulose in secondary cell wall of higher plant, Gluconacetobacter xylinus produced the cellulose composites in the presence of glucuronoxylan glucomanan, O-acetyl-glucuronoxylan, arabinoglucuronoxylan, arabinogalactan and xyloglucan.The cellulose composites were investigated by $\mathrm{X}$-ray diffraction and sugar analysis [48]. Differactions of bacterial celluloses cultured in the presence of xylan (Xyl) and arabinogalactan (AraGal) retain the plane orientation of $\mathrm{I}_{\alpha}$-rich form. In the cases of glucomannan (GlcMan) and xyloglucan (xylGlc) indicating the increase in the disordered structure in these celluloses. Hemicellulosic polysaccharide contents in bacterial celluloses cultured in the presence of hemicellulosic polysaccharides were $3.0 \%$ (arabinogalactan), 28.2\% (xylan), 48.6\% (glucomannan) and $47.0 \%$ (xyloglucan). Based on these results, glucomannan was concluded to have the highest affinity to bacterial cellulose [48]. Interaction between bacterial cellulose and glucomannan have been studied through molecular and ultrastructural analysis of composites formed by deposition of cellulose into solutions containing either glucomannan or galactomannans of varying Man:Gal ratio. 13C NMR suggests that unsubstituted mannan segments can bind to cellulose by undergoing a conformational transition to an extended 2 -fold form. The presence of cellulose fibrils promotes network formation from galactomannan solutions under conditions where this would not normally occur [49].

Carboxymethyl Cellulose (CMC): The effects of carboxymethyl cellulose (CMC) and xyloglucan (XG) added to the incubation medium were examined $[28,29]$. Because CMC and XG are known to interfere with the aggregation of microfibrils into normal ribbon assembly $[50,51]$. It was found that the mass fraction of cellulose $I_{\alpha}$ is greatly decreased with increasing concentration of CMC, XG in the incubation medium and this decrease in the mass fraction of cellulose $I_{\alpha}$ corresponds to the enhanced crystallization of cellulose $I_{\beta}$. Hence, the cause of the decrease in the fraction of cellulose $\mathrm{I}_{\beta}$ is expected to be associated with the reduction in the lateral width of microfibril induced by the addition of CMC or XG [50]. Recently, the effect of the $\mathrm{CMC}$ and $\mathrm{XG}$ additives with different degree of polymerization (DP) or substitution (DS) on the formation of the microfibril has been examined by transmission electron microscope (Hirai et al., 1998). $\mathrm{CMC}$ with $\mathrm{DP}=80$ and $\mathrm{DS}=0.57$ is the most effective in producing separate, smaller-size microfibrils. By increasing the concentration of CMC in cultivation medium from 0.1 to $1.5 \%$, the percentage of microfibrils measuring 3-7 nm wide is increased. Whereas, XG are less effective than $\mathrm{CMC}$ in producing microfibrils with smaller sizes and the resulting microfibrils still tend to aggregate.

Direct dyes: Gluconacetobacter xylinus normally produces crystalline $30 \AA$ microfibers in association with intracellular synthesizing sites in the lipopolysaccharide layer of the bacterium [52]. When actively synthesizing Gluconacetobacter xylinus cell were incubated in the medium or phosphate buffer containing more than
$0.01 \%$ calcofluor (fluorescent brightener), ribbon assembly was disrupted, instead of twisting ribbons and a broad bands of bent fibrils were formed [53]. High-resolution micrographs reveal that, the smallest fibrils in the band product measured $15 \AA$ ( $\pm 4 \AA)$ and larger fibrils appeared to arise by fascination of smaller $15 \AA$. Fibrils frequently show pronounced curvature and undulation, which suggest low crystallinity. While the larger aggregate often bend sharply and appear more rigid. The altered cellulose synthesized is known to be high molecular weight, noncrystalline $\beta-1,4-D$-glucans. X-ray crystallography indicate that, the calcofluor induce product of cellulose I crystallinity after drying although it had no detectable crystallinity in the wet state [52]. This lack of crystallinity before drying indicate that, calcofluor effectively separate polymerization from crystallization in the wet state by preventing microfibril assembly and the calcofluor induced products profoundly different from native bacterial cellulose [23]. On drying, the hydrogen bonds of the nascent crystal lattice must be so favorable than the association between calcofluor and glucan. So that, calcofluor is displaced and the cellulose I lattice form [23]. The effect of direct dyes was due to extensive lateral precipitation of the dyes onto the growing cellulose microcrystals, which prevented them from reaching their normal size [53]. A number of direct dyes (Direct Red 28, Direct Red 79, Direct Blue 14, Direct Blue 15, Direct Blue 53 and Direct Blue 75) were selected to clarify the effect of them on the nascent structure of bacterial cellulose [54-57]. Cellulose $\mathrm{IV}_{\mathrm{I}}$ and cellulose II are regenerated from Direct Red 28 and Direct Red 79, Direct Blue 14, Direct Blue 15, Direct Blue 53 and Direct Blue 75 complexes, respectively. According to the chemical structure of direct dyes which are used. The sulfonate group plays an important factor in the effect of direct dyes on the crystal structure of nascent bacterial cellulose. Kai and Keshk [58,23] confirmed the influence of sulfonate group by using four substituent of fluorescent brightener. All of them have the same skeletal structure (stilbene group) but the difference in number and position of sulfonate group. The fluorescent brightener substituent that has more sulfonyl group gave cellulose II after dye extraction. While fluorescent brightener substituent that has less sulfonyl group gave cellulose I after dye extraction [59].

DCB (2,6-dicholoronitrobenzonitrile): 2,6-dichlorobenzonitrile (DCB) is herbicide, which has been shown to be specific and effective inhibitor for cellulose synthesis in algae, higher plants and also bacteria. The extent of the inhibition is dependent on the concentration of DCB. Normally, the bacterial cellulose produced is in the cellulose I allomorph, which is predominant native form. Whereas in presence of $12 \mu \mathrm{M}$ DCB, a mixture of cellulose I and II allomorphs were formed. $\mathrm{X}$-ray diffraction method and Raman spectrum confirmed this result [60].

\section{Reactivity of BC toward chemical reaction}

Few researches have been discussed the chemical reactivity and either heterogeneous or homogenous reactions of $\mathrm{BC}[61,62]$.

Heterogeneous reaction: Bacterial cellulose differs from plant cellulose with respect to its high crystallinity and purity (free of lignin and other biogenic products), high water-absorption capacity and better mechanical strength [63]. The typical properties of BC have also inspired investigations on the reactivity and availability of the hydroxyl groups for chemical reactions as well as the subsequent characterization of the products obtained [61]. The carboxmethylation and cyanoethylation reactions were performed on $\mathrm{BC}$, viscose grade pulp and cotton linter to study the reactivity of these cellulose samples [61]. Bacterial cellulose differs from plant celluloses (viscose grade pulp and cotton linter) with respect to its high crystallinity and purity from 
lignin. $\mathrm{BC}$ is more reactive to cyanoethylation and carboxymethylation than that of plant cellulose according to its high crystallinity with low degree of polymerization [61].

Homogenous reaction: Homogenous reaction of dissolved $\mathrm{BC}$ with acetic anhydride and phenyl isocyanate showed products with high degree of substitution value up to 3.0 compared to plant cellulose without explaining the reason of this reactivity. Since cellulose dissolves in $85 \%$ phosphoric acid with limited hydrolysis, its homogenous oxidation of the primary hydroxyl groups with halogen oxides have been achieved. Interestingly, iodination of cellulose in $85 \%$ phosphoric acid using mixture of $\mathrm{KIO}_{3}$ and $\mathrm{KI}$ gave triester of hypoiodous acid. Homogenous derivatizations (selective Iodination and Oxidation) using phosphoric acid have been performed on different cellulose samples (BC, Kenaf and microcrystalline cellulose) to reveal their chemical reactivates and their physicochemical characterizations [64]. The results indicate that $\mathrm{BC}$ in phosphoric acid has the highest reactivity toward iodination reaction. This may be attributed to the use of phosphoric acid that degrades the crystal structure of cellulose. So the crystallinity does not play an important factor as in the case of heterogeneous reactions [61].

\section{Bacterial cellulose and medical application}

Due to its high purity, hydrophilicity, structure forming potential, chirality and biocompatibility offers a wide range of special applications, e.g. as a food matrix (nata de coco), as dietary fiber, as an acoustic or filter membrane, as ultra-strength paper and as reticulated fine fiber network with coating, binding, thickening and suspending characteristics up to now several applications of bacterial cellulose in human and veterinary medicine are known.

\section{Skin therapy}

The high mechanical strength in the wet state, substantial permeability for liquids and gases and low irritation of skin indicated that the gelatinous membrane of bacterial cellulose was usable as an artificial skin for temporary covering of wounds (Figure 4). Biofill ${ }^{\circledR}$ and Gengiflex $^{\circledR}$ are products of bacterial cellulose with wide applications in surgery and dental implants and realities in the human health-care sector. Cases of second and third degree of burns, ulcers and others could be treated successfully with Biofill ${ }^{\mathbb{Q}}$ as temporary substitute for human skin [65]. The authors documented the following advantages for Biofill ${ }^{\mathbb{B}}$ in more than 300 treatments: immediate pain relief, close adhesion to the wound bed, diminished post-surgery discomfort, reduced infection rate, easiness of wound inspection (transparency), faster healing, and improved exudates retention, spontaneous detachment following reepithelization, and reduced treatment time and costs.

Only one disadvantage, was mentioned: limited elasticity in areas of great mobility. Gengiflex was also developed to recover periodontal

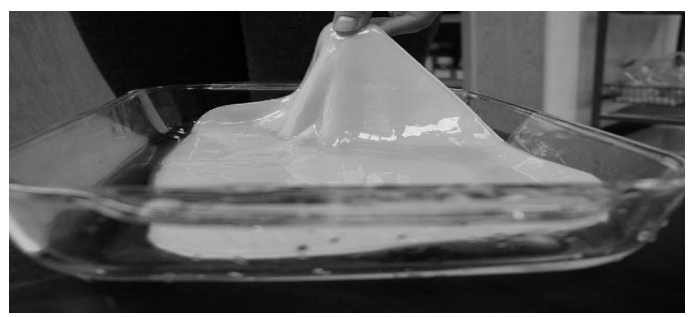

Figure 4: The never-dried bacterial cellulose membrane is a nonpyrogenic and fully biocompatible biomaterial with high mechanical strength. tissues. Further results and applications of both Biofill and Gengiflex were published by different authors. Schmauder et al., described the application of bacterial cellulose (Cellumed) in veterinary medicine to treat recent, large surface wounds on horses and dogs [66].

\section{Artificial blood vessels}

If the coronary vessels around the heart are blocked as a result of hardening of the arteries, it may be necessary to carry out a bypass operation. The cellulose produced by bacteria could be used for artificial blood vessels as it carries a lower risk of blood clots than the synthetic materials currently used for bypass operations. BC can carry a lower risk of blood clots than the synthetic materials currently in use. This means that the cellulose works very well in contact with the blood and is a very interesting alternative for artificial blood vessels. Real blood vessels have an internal coating of cells that ensure that the blood does not clot. This tube has an inner diameter of $1 \mathrm{~mm}$, length of about 5 $\mathrm{mm}$ and wall thickness of $0.7 \mathrm{~mm}$. So these parameters are sufficient for experimental microsurgical requirements. A sufficient mechanical strength of the BASYC tubes is one of the essential properties for their use in microsurgery. The material must resist both mechanical strains during microsurgical preparation and anatomizing and blood pressure of the living body. The native bacterial cellulose has mechanical properties, including shape retention and tear resistance, which are superior to many synthetic materials. In comparison with organic sheets, like polypropylene, polyethylene-terephthalate or cellophane. BC processed into a film or sheet show remarkable mechanical strength. Compliance mismatch between the synthetic graft and the surrounding native tissue has been reported as a major factor in ultimate failure of the currently used cardiovascular graft replacements. Thus, developing biomaterials that display close mechanical properties as the tissue it is replacing is an important objective in biomedical devices design. Polyvinyl alcohol (PVA) is a biocompatible hydrogel with characteristics desired for biomedical applications. It can be cross linked by a low temperature thermal cycling process. By using a novel thermal processing method under an applied strain and with the addition of a small amount of bacterial cellulose (BC) nano fibers, an anisotropic PVA-BC nano composite was created. The stress-strain tensile properties of porcine aorta were closely matched in both the circumferential and the axial directions by one type of anisotropic PVA-BC nano composite (10\% PVA with $0.3 \%$ BC at $75 \%$ initial strain and cycle 2) within physiological range, with improved resistance to further stretch beyond physiological strains. The PVA-BC nano composite gives a broad range of mechanical properties, including anisotropy, by controlling material and processing parameters. PVA$\mathrm{BC}$ nano composites with controlled degree of anisotropy that closely match the mechanical properties of the soft tissue it might replace, ranging from cardiovascular to other connective tissues, can be created. Where, $\mathrm{BC}$ has been investigated as a potential new vascular graft material by evaluating cell and blood interactions with BC. The specific aims were to evaluate if surface modifications could promote human endothelial cells and to investigate the thrombogenic properties of BC compared to conventional graft materials. Modification of $\mathrm{BC}$ with a novel technique, were xyloglucan is used as a carrier molecule for the adhesion-promoting peptide RGD, resulted in increased cell adhesion, metabolism and cell spreading. Luminal coating of BC-tubes with fibrin glue resulted in increased cell adhesion during static experiments and good cell retention during physiological shear stress. The evaluation of thrombogenicity in human blood plasma revealed that $\mathrm{BC}$ induces a slower coagulation compared with clinically available materials such as Gore-Tex ${ }^{\circledR}$ and Dacron ${ }^{\circledR}$. In addition, BC induced the least contact activation evaluated by XIIa generation. A Chandler loop system 
with freshly drawn blood showed that BC consumed low amounts of platelets and generated low thrombin values compared with Dacron ${ }^{\circledR}$ and Gore-Tex ${ }^{\mathbb{B}}$.

\section{Potential scaffold for tissue engineering}

The use of scaffolds in the tissue engineering of cartilage is essential in order to support cell proliferation and maintain their differentiated function in addition to definition of the shape of the new growing tissue. To this end, a variety of scaffold materials have been evaluated including natural polymers like collagen, alginate, hyaluronic acid, fibrin glue and chitosan and synthetic polymers including poly glycolic acid (PGA),polylactic acid (PLA), polyvinyl alcohol (PVA), polyhydroxy ethyl methacrylate (pHEMA) and polyN iso propyl acryl amide (pNIPAA). However, tissue constructs with native mechanical properties have not yet been described in the literature. G. xylinus was explored as a novel scaffold material due to its unusual material properties and degradability. Native and chemically modified BC materials (phosphorated and sulfonated BCs) were evaluated using bovine chondrocytes. The results indicate that unmodified BC supports chondrocyte proliferation at levels of approximately $50 \%$ of the collagen type II substrate while providing significant advantages in terms of mechanical properties. Compared to tissue culture plastic and calcium alginate, unmodified BC showed significantly higher levels of chondrocyte growth. Chemical sulfonation and phosphorylation of BC, performed to mimic the glucose amino glycans of native cartilage, did not enhance chondrocyte growth while the porosity of the material did affect chondrocyte viability. BC did not induce significant activation of pro-inflammatory cytokine production during in vitro macrophage screening. Hence, unmodified $\mathrm{BC}$ was further explored using human chondrocytes. TEM analysis and RNA expression of the collagen II from human chondrocytes indicated that unmodified BC supports proliferation of chondrocytes. In addition, in growth of chondrocytes into the scaffold was verified by TEM. The results suggest the potential for this biomaterial as a scaffold for tissue engineering of cartilage.

\section{Wound care products}

In the early 1980's Johnson \& Johnson pioneered in exploratory investigations on the use of microbial cellulose as a liquid loaded pad for wound care (see US Patent 4,655,758; 4,588,400). Since that time, a company in Brazil, Biolfill Industries, has continued to investigate the properties of microbial cellulose and is beginning to market specific microbial cellulose products in the wound care market [65,67]. In Brazil, the purified gelatinous membrane of bacterial cellulose was developed and commercialized as an artificial skin (wound dressing) [65]. A high mechanical strength in the wet state, substantial permeability for liquids and gases and low irritation of skin, indicated that the gelatinous membrane of the bacterial cellulose was superior to conventional quaze as an artificial skin for temporary covering off wounds [67]. Bacterial cellulose composites made by blending chitosan, poly (ethylene glycol) (PEG), and gelatin for potential biomedical application of tissueengineering scaffold and wound-dressing material [68]. The bacterial cellulose composites were successfully prepared by immersing a wet bacterial cellulose pellicle into chitosan, PEG, or gelatin solutions followed by freeze-drying. The products look like a foam structure. Scanning electron microscopy images show that chitosan molecules penetrated into bacterial cellulose forming a multilayer and a well interconnected porous network structure with a large aspect surface. The morphology of the bacterial cellulose/gelatin scaffold indicates that the gelatin molecules could penetrate well between the individual nano-fibers of the bacterial cellulose. Cell adhesion studies for these composites were carried out using 3T3 fibroblast cells [69]. They showed much better biocompatibility than pure bacterial cellulose.

\section{Tablet modification}

A new preparation method of microcrystalline cellulose from $G$. xylinus (BC) and kenaf (KF) is reported [63]. The developed cellulose (DBC and DKF) materials showed different crystalline structures. DBC exhibited cellulose I lattice with high crystallinity (85\%) whereas DKF showed cellulose II lattice with high crystalinity (70\%) The particle size of DKF was 5-20 $\mu \mathrm{m}$ while that of DBC was $1-5 \mu \mathrm{m}$. The physical properties of the DBC and DKF materials were compared with those of the commercially available microcrystalline cellulose Avicel ${ }^{\mathbb{B}} \mathrm{PH}$ 101. DBC exhibited lower value of the loose density than those of DKF and Avicel PH 101 [70-74]. Both microcrystalline DBC and Avicel PH 101 demonstrated similar behavior during flow and binding processes. The thermal properties of DBC and DKF materials were investigated by thermo-gravimetric analysis [75]. The TGA results reveal increased thermal stability for DBC compared to DKF. Moreover, the weight loss of $\mathrm{DBC}$ occurred in one step degradation process from about $320^{\circ} \mathrm{C}$ to $380^{\circ} \mathrm{C}$, which is mainly due to the decomposition of cellulose. These differences in the thermal properties of both cellulose materials are mainly due to differences in their degree of crystallinity. This agrees with XRD data where DBC exhibits $85 \%$ degree of crystallinity and DKF 77\%. This revealed a relationship between crystal structure and the thermal degradation of cellulose. A greater crystalline structure required a higher degradation temperature and, therefore, DBC degraded at $320^{\circ} \mathrm{C}$ whereas $\mathrm{DKF}$ at $215^{\circ} \mathrm{C}$.

\section{Bacterial cellulose and paper industry}

Microbial cellulose has been investigated as a binder in papers, and because it consists of extremely small clusters of cellulose microfibrils, this property greatly adds to strength and durability of pulp when integrated into paper. Ajinomoto Co. along with Mitsubishi Paper Mills in Japan are currently active in developing microbial cellulose for paper products (JP patent 63295793 and [68]. Moreover, when the agitated bacterial cellulose and static bacterial cellulose were added at wetend, both tensile strength and filler retention of the hand sheets were improved [69]. Especially, the bacterial cellulose from agitated culture had higher effects on filler-retention than that from static one. Thus the bacterial cellulose may be useful as a wet-end additive for papermaking. Furthermore, Suspended solids in the nutrient medium for A. xylinium in a rotating disk bioreactor become incorporated into the gelatinous mat of bacterial cellulose as it forms [76]. Embedding fibers of ordinary cellulose creates composites with enhanced strength and the toughness of bacterial cellulose. Purified cellulose and elongated fibers from paper are incorporated differently than are spherical particles such as silica gel. About $90 \%$ of the final cellulose can come from scrap paper, and dried composite sheets were much stronger than plain bacterial cellulose per unit area. Basta and Elsaied [70] confirmed that incorporating $5 \%$ of $\mathrm{BC}$ with wood pulp during paper sheet formation was found to significantly improve kaolin retention, strength, and fire resistance properties as compared to paper sheets produced from incorporating $\mathrm{BC}[76]$.

\section{Bacteial cellulose and food industry}

The Philippine desert, Nata de Coco, has been a cottage industry for the past seventy years in the Philippines [77]. The import of Nata from the Philippines into Japan has had a major impact on the global outlook for expansion of microbial cellulose production. In 1992, a fad originated in Japan with the introduction of microbial cellulose into diet drinks. As a result of production of Nata de Coco through G. xylinus, David [78] 
showed that Nata de Coco has the plasma cholesterol-lowering effect. In which the coconut milk was incubated with the G.xylinus as a carbon source. BC has been applied as a functional food additive as a thickener and disperser, in these applications for food; the bacterial cellulose from agitated culture has a much higher emulsifying effect than that from static culture [79]. Monascus-bacterial cellulose complex, which combined the properties of bacterial cellulose and Monascus fungi, showed the potential to be a new foodstuff as vegetarian meat or seafood replacement. Growth of Monascus mycelium did not impart a flavor to this new product creating it a good base as a flavor-added food. The color and texture of the complex were like liver or lean meat. It also provides high fiber content, limited calories and healthy nutrients. Moreover, the waste broth from the fermentation could be further used as a source of water-soluble pigments. Moreover, Shirai et al. [80] reported that, gelatinous cellulose prepared by fermentation with Acetobacter acet $i$ AJ 12368 consisted of cellulose fibrils (0.9\%), bound water $(0.3 \%)$ and free water $(98.8 \%)$. The cellulose network absorbed water weakly in capillaries of about 0.5-1.0 microns. When stressed the gel released its water and deformed without fracture. The gel by itself was too tough to bite, but it became edible through processing either with sugar alcohol or with alginate and calcium chloride. The textures resemble fruit, such as grapes and molluscs such as squids, respectively. The mechanism is the immobilization of the water of gelatinous cellulose by viscous or gel-forming material, and accordingly the gel becomes easy to cut off with the teeth. These results show that gelatinous cellulose with its fibrous texture can be a new material for salads, low-calorie desserts, fabricated foods.

\section{Future prospective and conclusions}

Economic feasibility of bacterial cellulose is primarily dependent on its productivity. The choice of fermentor design is particularly critical because it must withstand vigorous mechanical agitation of the rapidly growing $A$. xylinum (obligate aerobe) culture, and also prevent the cellulose fibril and fibrillar matrix from mechanical disruption. Agitated culture results in highly branched, threedimensional, reticulated structure, whereas static culture produces a normal cellulose pellicle with a lamellar structure and less significant branching. Desirable modifications in the fibrillar and/or macroscopic nature of the cellulosic product may be achieved by varying fermentor design factors such as the shape of vessels and agitating impellers. The advantage of the stirred tank reactor is its ability to prevent the heterogeneity of the culture broth by strong mechanical agitation, while its drawback is high energy cost for generating the mechanical power. On the contrary, the energy cost of an airlift reactor is one sixth of that of a stirred tank reactor. However, the agitation power of an airlift reactor is limited, resulting in low fluidity of the culture broth, especially at high cellulose concentrations. To meet different demands, the combined use of an airlift and a stirred tank reactors, or continuous cultivation, may be a possible solution. Use of some modified reactors like rotating disk reactor, rotary biofilm contactor, bioreactors equipped with a spin filter or reactor with silicone membrane can also be a useful solution. One of the major obstacles encountered in the industrial adaptation of A. xylinum is the wasteful and noxious accumulation of metabolic byproducts.

\section{References}

1. Kai A, Arashida T, Hatanaka K, Akaike T, Matsuzaki K, et al. (1994) Analysis of the biosynthetic process of cellulose and curdlan using ${ }^{13} \mathrm{C}$-labeled glucose. Carbohyd Polym 23: 235-239.

2. Delmer PD, Yehudit A (1995) Cellulose biosynthesis. The Plant Cell 7: 9871000
3. Tonouchi N, Tsuchida T, Yoshinaga F Beppu T, Horinouchi S (1996) Characterization of the biosynthetic pathway of cellulose from glucose and fructose in Acetobacter xylinum. Biosci Biotech Biochem 60: 1377-1379.

4. Yoshinaga F, Tonouchi N, Watanabe K (1997) Research progress in production of bacterial cellulose by aeration and agitation culture and its application as a new industrial material. Biosci Biotech Biochem 61: 219-224.

5. Montezinos D, Brown Jr RM (1976) Cellulose microfibrils. Proc Natl Acad Sci USA 84: 6985- 6989.

6. Son HJ, Heo MS, Kim YG, Lee SJ (2001) Optimization of fermentation conditions for the production of bacterial cellulose by a newly isolated Acetobacter. Biotechnol Appl Biochem 33: 1-5.

7. Colvin JR (1980) The biosynthesis of cellulose: Plant biochemistry, Academic Press Inc., New York: 543-570.

8. Ross P, Mayer R, Benziman M (1991) Cellulose biosynthesis and function in bacteria. Microbiol Rev 55: 35-58.

9. Tanaka M, Murakami S, Shinke R, Aoki K (2000) Genetic characteristics of cellulose-forming acetic acid bacteria identified phenotypically as Gluconacetobacter xylinus. Biosci Biotechnol Biochem 64: 757-60.

10. Matthysse AG, Thomas, DOL, White AR (1995) Mechanism of cellulose synthesis in Agrobacterium tumefaciens. J Bacteriology 177: 1076-1081.

11. Matthysse AG, white $S$, Lightfoot $R$ (1995) Genes required for cellulose synthesis in Agrobacterium tumefaciens. J Bacteriology 177: 1069-1075.

12. Koyama M, Sugiyama J, Itoh T (1997) Systematic survey on crystalline features of algal celluloses. Cellulose 4: 147-160.

13. Blanton RL, Northcote DH (1990) A 1,4- $\beta$-D-glucan synthase system from Dictyostelium discoideum Planta 180: 324-332.

14. Bulone V, GIrard V, Fevre M (1990) Separation and partial purification of $1,3-\beta$-glucan and 1,4- $\beta$-glucan synthases from Saprolegnia. Plant Physiol 94 1748-1755.

15. Ryser U (1985) Cell wall biosynthesis in differentiating cotton fibers. Eur J Cell Biol 39: 236-265

16. Ross P, Weinhouse H, Aloni Y, Michaeli D, Ohana P, et al. (1987) Regulation of cellulose synthesis in Acetobacter xylinum by cyclic diguanylic acid. Nature (London) 325: 279-281.

17. Boisset C, Chanzy H, Henrissat B, Lamed R, Shoham Y, et al. (1999) Digestion of crystalline cellulose substrates by the clostridium thermocellum cellulosome: structural and morphological aspects. Biochem J 340: 829-835.

18. Chang AL, Tuckerman JR, Gonzalez G, Mayer R, Weinhouse H, et al., (2001) Regulator of cellulose synthesis in Acetobacter xylinum. Biochem 40: 34203426

19. Kimura S, Chen HP, Saxena IM, Brown RM, Itoh T (2001) Localization of c-di-GMP-binding protein with the linear terminal complexes of Acetobacter xylinum. J Bacteriol 183: 5668-5674.

20. Wang X, Cnops G, Vanderhaeghen R, Block S, Montagu M, et al., (2001) AtCSLD3, Cellulose synthase-like gene important for root hair growth in arabidopsis. Plant Physiol 126: 575-586.

21. Vergara CE, Carpita NC (2001) Beta-D-glycan synthases and the CesA gene family: lessons to be learned from the mixed-linkage (1-->3),(1-->4)beta-D glucan synthase. Plant Mol Biol 47: 145-160.

22. Vanderhart DL, Atalla RH (1984) Studies of microstructure in native cellulose using solid-state 13C NMR. Macromolecules 17: 1465-1472.

23. Keshk SMA (1999) Nascent structure of microbial cellulose. Ph.D. Thesis Tokyo Metropolitan University.

24. Hirai A, Horii F, Kitamaru R (1987) Transformation of native cellulose crystals from cellulose $\mathrm{Ib}$ to la through solid state chemical reactions. Macromolecules 20: $1440-1442$.

25. Horii F, Yamamoto $H$, Hirai A (1997) Microstructural analysis of microfibrils of bacterial cellulose. Macromol Symp 120: 197-205.

26. Yamamoto H, Horii F (1993) CP/Mass Carbon- 13 NMR analysis of the crystal transformation induced for Valonia cellulose by annealing at high temperatures. Macromolecules 26: 1313-1317. 
Citation: Keshk SMAS (2014) Bacterial Cellulose Production and its Industrial Applications. J Bioprocess Biotech 4: 150 doi: $10.4172 / 2155-$ 9821.1000150

Page 9 of 10

27. Hirai A, Masaki T, Yamamoto $H$, Horii $F$ (1998) In situ crystallization of bacterial cellulose III. Influences of different polymeric additives on the formation of microfibrils as revealed by transmission electron microscopy. Cellulose 5: 201 213.

28. Yamamoto $H$, Horii $F$ (1994) In situ crystallization of bacterial cellulose I. Influences of polymeric additives, stirring and temperature on the formation cellulose $\mathrm{l} \alpha$ and $\mathrm{I} \beta$ as revealed by cross polarization/magic angle spinning (CP Mass) 13C NMR spectroscopy. Cellulose 1: 57.

29. Yamamoto $H$, Horii F, Hirai A (1996) In situ crystallization of bacterial cellulose II. Influences of polymeric additives with different molecular weight on the formation cellulose l $\alpha$ and $I \beta$ at the early stage of incubation. Cellulose 3: 229242

30. Haigler $\mathrm{CH}$, Weimer PJ (1991) Biosynthesis and biodegradation of cellulose. Marcel Dekker, Inc. New York, USA

31. Watanabe K, Tabuchi M, Morinaga Y, Yoshiinaga F (1998) Structural features and properties of bacterial cellulose produced in agitated culture. Cellulose 5 : $187-200$

32. Hiroshi O, Watanabe K, Morinaga Y, Yoshinaga F (1997) Emulsion-stabilizing effect of bacterial cellulose. Biosci Biotech Biochem 61: 1541-1545.

33. Hestrin S, Schramm M (1954) Synthesis of cellulose by Acetobacter xylinum. 2. Preperation of freeze-dried ceels capable of polymerizing glucose to cellulose. Biochem J 58: 345-352.

34. Masaoka S, Ohe T, Sakota N (1993) Production of cellulose from glucose by Acetobacter xylinum. J Fermen Bioeng 75: 18-22.

35. Oikawa T, Morino T, Ameyama M (1995) Production of cellulose from D-Arbito by Acetobacter xylinum KU-1. Biosci Biotech Biochem 59: 1564-1565.

36. Tajima K, Fujiwara M, Takai M (1995) Biological control of cellulose. Macromol Symp 99: 149-155

37. Embuscado M, Marks J, Bemiller J (1994) Bacterial cellulose. I. Factors affecting the production of cellulose by Acetobacter xylinum. Food Hydro 8 : 407-418

38. Embuscado M, Marks J, Bemiller J (1994) Bacterial cellulose. II. Optimization of cellulose production by Acetobacter xylinum through response surface methodology. Food Hydro 8: 419-430.

39. Delmer PD (1999) Cellulose biosynthesis: Exciting times for a difficult field of study. Annu Rev Plant Physiol Plant Mol Biol 50: 245-76.

40. Tonouchi N, Tahara N, Tsuchida T, Yoshinaga F, Beppu T (1995) Addition of a small amount of an endoglucanase enhances cellulose production by Acetobacter xylinum. Biosci Biotech Biochem 59: 805-808.

41. Premjet S, Ohtani O, Someshima K (1994) The contribution of high molecular lignosulfonate to the powerful bacterial cellulose production system with Acetobacter xylinum ATCC 10245. Sen'i Gakkaishi 50: 458-463.

42. Premjet S, Ohtani Y, Saeshima K (1996) X-ray diffraction diagram of the bacterial cellulose membrane produced by Acetobacter xylinum in the medium with lignosulfonate. Sen, i Gakkaishi 52: 169-174. 42

43. Keshk SMAS (2014) Vitamin C Enhances Bacterial Cellulose Production in Gluconacetobacter Xylinus. Carbohydrate Polymer 99: 98-100.

44. Keshk SMAS, Suwinarti W, Sameshima K (2006) Physicochemical Characterization of Different Treatment Sequences on Kenaf Bast Fiber. Carbohydr Polym 65: 202-206.

45. Yamanaka S, Watanabe K, Kitamura N, Iguchi M, Mitsuhashi S, et al. (1989) The structure and mechanical properties of sheets prepared from bacterial cellulose. J Mater Sci 24: 3141-3145.

46. Hackney J, Atalla R, Vanderhart D (1994) Modification of crystallinity and crystalline structure of Acetobacter xylinum in the presence of water-soluble beta-1,4-linked polysaccharides: 13C-NMR evidence. Int J Biol Macromol 16 215-218.

47. Uhlin K, Atalla R, Thompson N (1995) Influence of hemicelluloses on the aggregation patterns of bacterial cellulose. Cellulose 2: 129-144.

48. Iwata T, Indrarti L, Azuma J (1998) Affinity of hemicellulose for cellulose produced by Acetobacter xylinum. Cellulose 5: 215-228.

49. Whitney S, Brigham J, Darke A, Grant Reid J, Gidley M (1998) Structura aspects of the interaction of mannan-based polysaccharides with bacterial cellulose. Carbohyd Res 307: 299-309.

50. Haigler H, White R, Brown M, Cooper M (1982) Alteration of in vivo cellulose ribbon assembly by carboxymethylcellulose and other cellulose derivatives. J Cell Biol 94: 64-69.

51. Hayashi T, Marsden E, Delmer P (1987) Pea xyloglucan and cellulose: VI. Xyloglucan cellulose interactions in vitro and in vivo. Plant Physiol 83: 384-389.

52. Haigler H, Brown M, Benziman M (1980) Calcofluor white ST alters the in vivo assembly of cellulose microfibrils. Science 210: 903-906.

53. Haigler H, Chanzy H (1988) Electron diffraction analysis of the altered cellulose synthesized by Acetobacter xylinum in the presence of fluorescent brightening agents and direct dyes. J Ultrastruct Mol Struct Res 98: 299-311.

54. Kai A, Mondal IH (1997) Influence of substituent of direct dye having bisphenylenebis (azo) skeletal structure on structure of nascent cellulose produced by Acetobacter xylinum [I]: different influence of direct red 28, blue 1 and 15 on nascent structure. Int J Biol Macromolecules 20: 221-231.

55. Mondal I, Kai A (1998) Structure of nascent microbial cellulose I. Effects of methyl and methoxy groups of direct blue 1 and 53 on nascent microbial cellulose. Polym J 30: 78-83.

56. Mondal I, Kai A (1998) Structure of nascent microbial cellulose II. Effects of methyl and methoxy groups of direct blue 14 and 15 on nascent microbial cellulose. Polym J 30: 84-89.

57. Mondal I, Kai A (1999) Influence of substitution of direct dye having biphenylenebis (azo) skeletal structure on structure of nascent cellulose produced by Acetobacter xylinum [II]. J Appl Poly Sci 71: 1007-1015.

58. Kai A, Keshk SMA (1998) Structure of nascent microbial cellulose V. Influence of positions of sulfonate groups in fluorescent brightener on crystal structure of microbial cellulose. Polym J 30: 996-1000.

59. Keshk SMA, Kai A (2000) Influence of numbers and positions of sulfonate group in fluorescent brightener on nascent structure of bacterial cellulose. The $6^{\text {t }}$ Arab international Conference on Materials Science 1: 115, Alexandria, Egypt.

60. Yu X, Atalla R (1996) Production of cellulose II by Acetobacter xylinum in the presence of 2,6-dichlorobenzonitrile. Int J Biol Macromol 19: 145-146.

61. Keshk SMAS, Nada A (2003) Heterogeneous Derivatization of Bacterial and Plant Celluloses. Biotech Biosci Asia 1: 39.

62. Keshk SMAS, Sameshima K (2005) Evaluation of Different Carbon Sources for the Production of Bacterial Cellulose. Afri J Biotech 4: 478-482.

63. Keshk SMAS, Haijia M (2011) A New Method for Producing Microcrystalline Cellulose from Gluconacetobacter xylinus and Kenaf. Carbohydr Polym 84: 1301-1305.

64. Keshk SMAS (2008) Homogenous Reaction of Cellulose from Different Natura Sources. Carbohydr Polym 74: 942-945.

65. Fontana JD, Souza A M, Fontana CK, Toriani IL, Moreschi JC, et al. (1990) Acetobacter cellulose pellicle as a temporary skin substitute. Appl Biochem Biotechnol 24-25: 253-264.

66. Kawecki M, Krystynowicz A, Wysota K, Czaja W, Sakiel S, et al. (2004) Bacterial cellulose biosynthesis, properties and applications. International Review Conference Biotechnology, Vienna, Austria, 14-18.

67. Fontana JD, Franco VC, Souza SJ, Lyra IN, Souza AM (1991) Nature of plant stimulators in the production of Acetobacter xylinum ("Tea Fungus") biofilm used in skin therapy. Appl Biochem Biotechnol 28-29: 341-351.

68. Ougiya H, Watanabe K, Morinaga Y, Yoshinaga F (1997) Emulsion effect of bacterial cellulose. Biosci Biotech Biochem 61: 1541-1545.

69. Hioki N, Hori Y, Watanabe K, Morinaga Y, Yoshinaga F, et al. (1995) Bacterial cellulose; as a new material for papermaking. Kami-Gikyo-Shi 49: 82-87.

70. Basta AH, El-Saied H (2009) Performance of improved bacterial cellulose application in the production of functional paper. J Appl Microbiol 107: 2098107

71. Lapuz MM, Gallardo EG, Palo MA (1969) The nata organism-cultura requirements, characteristics and identity. The philippine $J$ of Science 96: 91 109

72. Kuwana Y (1997) Production and new function of Nata de Coco. Cell Commun 4: $25-28$. 
Citation: Keshk SMAS (2014) Bacterial Cellulose Production and its Industrial Applications. J Bioprocess Biotech 4: 150 doi: $10.4172 / 2155-$ 9821.1000150

Page 10 of 10

73. Brown Jr RM, Willison JHM, Richardson CL (1976) Cellulose biosynthesis in Acetobacter xylinum. Proc Nat Acad Sci USA 73: 4565-4569.

74. Czaja W, Krystynowicz A, Bielecki S, Brown Jr RM (2006) Microbial cellulose the natural power to heal wounds. Biomater 27: 145-151.

75. Gouda M, Keshk SMAS (2010) Evaluation of Multifunctional Properties of Cotton Fabric Based on Chitosan-Metal Film. Carbohydr Polym 80: 504-512.

76. Kai A, Keshk SMA (1999) Structure of nascent microbial cellulose VI. Influence of positions of sulfonate groups in fluorescent brightener on crystal structure of microbial cellulose. Polym J 31: 61-65.

77. Keshk SMAS, Sameshima K (2006) Utilization of Sugar Cane Molasses
With/without the Presence of Lignosulfonate for the Production of Bacterial Cellulose. Appl Microb Biotech 72: 291-296.

78. David NS (1996) Chemical modification of Lignocellulosic Materials: Chemical structures of cellulose, hemicelluloses and lignin, Marcel Dekker. Inc., New York, USA.

79. Ogawa R, Tokura S (1992) Preparation of bacterial cellulose containing $\mathrm{N}$-acetylglucosamine residues. Carbohydr Polym 19: 171-178.

80. Shirai A, Takahashi M, Kaneko H, Nishimura S, Ogawa M, et al. (1994) Biosynthesis of novel polysaccharide by Acetobacter xylinum. Int $\mathrm{J}$ Bio Macromol 16: 297-300. 